Jurnal Indonesia Sosial Teknologi: p-ISSN: 2723 - 6609

e-ISSN : 2745-5254

Vol. 2, No. 9 September 2021

\title{
EVALUASI PROGRAM GENERASI BERENCANA DI DKI JAKARTA
}

\author{
Dewi Kartika Sari' ${ }^{1}$, Khaerul Umam Noer ${ }^{2}$ \\ Program Pascasarjana Ilmu Administrasi Universitas Muhammadiyah Jakarta ${ }^{1,2}$ \\ Email: dewiks.dpr@gmail.com ${ }^{1}$,umam.noer@umj.ac.id ${ }^{2}$
}

\begin{abstract}
Abstrak
Tulisan ini bertujuan untuk mengevaluasi program Generasi Berencana (GenRe Ceria), khususnya pada akses kesehatan reproduksi, yang dilaksanakan oleh Badan Kependudukan dan Keluarga Berencana Nasional Provinsi DKI Jakarta yang menyasar pada anak perempuan sebagai subjek kebijakan dengan menggunakan CIPP Evaluation Model. Data BKKBN menyebut 57.688.472 jiwa yang berada dalam rentang usia remaja, artinya satu dari setiap 4 orang penduduk Indonesia adalah remaja. Jumlah yang sangat besar tersebut adalah potensi yang memerlukan pengelolaan yang terencana, sistematis dan terstruktur agar dapat bermanfaat bagi modal pembangunan bangsa ke depan. Genre Ceria dimulai pada 2015 dan berakhir pada 2020, dengan pendekatan kepada remaja melalui wadah pengembangan Pusat Informasi dan Konseling Remaja/Mahasiswa (PIK R/M) di sekolah. Penelitian ini menggunakan metode penelitian kualitatif, dengan wawancara delapan belas informan dan observasi di di enam sekolah di DKI Jakarta Barat yang menjadi ujung tombak dalam upaya memberikan akses layanan dan informasi kesehatan reproduksi bagi remaja perempuan. Hasil penelitian menunjukkan bahwa program Genre Ceria yang digagas oleh BKKBN DKI Jakarta berjalan optimal meski cenderung terfokus pada remaja yang masih bersekolah, mengabaikan remaja yang putus sekolah dan ketidakmampuan memahami situasi kultural masyarakat.
\end{abstract}

Kata kunci: kesehatan reproduksi; CIPP Evaluation Model; remaja perempuan; HIV/AIDS; perkawinan anak

\begin{abstract}
This paper aims to evaluate the Generation Planning (Generasi Berencana/GenRe Ceria) program, particularly in access to reproductive health, implemented by the National Population and Family Planning Agency (BKKBN) of DKI Jakarta Province which targets girls as policy subjects using the CIPP Evaluation Model. BKKBN data mentions 57,688,472 people who are in the adolescent age range, meaning that one out of every 4 people in Indonesia is a teenager. This very large amount is a potential that requires a planned, systematic and structured management so that it can be beneficial for the nation's development capital in the future. The Genre Ceria program began in 2015 and ended in 2020, with an approach to youth through the development of the Youth/Student Information and Counseling Center (PIK R/M) in schools. This study uses qualitative research methods, with interviews with eighteen informants and observations in six schools in DKI Jakarta Barat who are spearheading efforts to provide access to reproductive health services and information for adolescent girls. The results show
\end{abstract}


that the Genre Ceria program runs optimally although it tends to focus on teenagers who are still in school, ignoring teenagers who drop out of school and the inability to understand the cultural situation of the community.

Keyword: reproduction health; CIPP Evaluation Model; teenage girls; HIV/AIDS; child marriage

\section{Pendahuluan}

Penelitian ini berfokus pada evaluasi program Generasi Berencana (selanjutnya disingkat GenRe), khususnya pada pelayanan akses dan informasi kesehatan reproduksi, yang dilaksanakan oleh Badan Kependudukan dan Keluarga Berencana Nasional Provinsi DKI Jakarta yang menyasar pada anak perempuan sebagai subjek kebijakan. UU 52/2009 tentang Perkembangan Kependudukan dan Pembangunan Keluarga mengamanatkan bahwa kebijakan pembangunan keluarga dilakukan melalui pembinaan ketahanan dan kesejahteraan keluarga, antara lain dengan cara meningkatkan kualitas hidup remaja melalui perluasan akses informasi, pendidikan, konseling dan pelayanan tentang kehidupan berkeluarga. Hal ini diperkuat dengan Peraturan Pemerintah 87/2014 tentang Perkembangan Kependudukan dan Pembangunan Keluarga, Keluarga Berencana dan Sistem Informasi Keluarga yang menyatakan bahwa pengembangan ketahanan dan kesejahteraan keluarga dilakukan dengan cara membentuk dan mengembangkan Pusat Informasi dan Konseling Kesehatan Reproduksi Remaja (Yulianti, 2017). Secara umum, BKKBN menyebut sejumlah masalah yang muncul di kelompok penduduk usia remaja, antara lain kesehatan reproduksi, HIV/AIDS, perkawinan anak, serta penyalahgunaan narkotika. Persoalan reproduksi menjadi penting, sebab berkaitan dengan rendahnya pengetahuan remaja tentang kesehatan reproduksi dan median usia kawin pertama perempuan relatif masih rendah.

Pada tahun 2015, BKKBN membuat dan melaksanakan beberapa program yang dirangkum dalam Program Kependudukan Keluarga Berencana dan Pembangunan Keluarga (KKBPK). Salah satu Program yang dilakukan dalam Program KKBPK tersebut adalah Program Generasi Berencana (GenRe Ceria) yaitu suatu program yang dilaksanakan melalui pendekatan dari dua sisi, yaitu pendekatan kepada remaja itu sendiri dan pendekatan kepada keluarga yang memiliki anak usia remaja. Pendekatan kepada remaja melalui wadah pengembangan Pusat Informasi dan Konseling Remaja/Mahasiswa (PIK R/M) di sekolah, sedangkan pendekatan kepada keluarga dilakukan melalui pengembangan kelompok Bina Keluarga Remaja.

Salah satu masalah krusialnya adalah, bahwa berbagai kajian mengenai program Generasi Berencana yang dilakukan oleh BKKBN umumnya hanya dilihat sebagai strategi pemerintah untuk mengatasi masalah pembangunan manusia khususnya remaja, di mana program ini berfokus pada pembinaan remaja Indonesia menjadi remaja visioner yang terhindar dari resiko Triad KRR, yakni seksualitas, HIV/AIDS dan Napza (Liana, 2018; Pyas \& Satlita, 2017; Devi Dwi Yana Utami, 2015; Yulianti, 2017). Meski ada pula yang berfokus pada jaringan kerja komunikasi dan kampanye yang dilakukan oleh BKKBN dalam mensosialisasikan program generasi berencana 
(Fitriyanti \& Iswari, 2020; Putri \& Larasati, 2015; Ridwan, Juhaepa, \& Sarmadan, 2019; Susanti, 2015). Kajian yang paling banyak dilakukan berfokus pada aspek sosialisasi pembinaan karakter yang merupakan salah satu aspek penting bagi remaja dalam menemukan dan mengembangkan jati diri supaya tidak terburu-buru untuk melakukan pernikahan dini (Citrawathi, Adnyana, Putu, \& Ratna, 2019; Daud \& Dasmidar, 2017; Oktavia, Achdiani, \& Rinekasari, 2016; Sari \& Indrawadi, 2019).

Berbagai yang ada memiliki sejumlah keterbatasan. Pertama, dengan fokus hanya pada persoalan kampanye dan sosialisasi, berbagai penelitian yang ada lebih fokus pada konten disebarluaskan di level bawah. Hal ini mengabaikan gejala mendasar bagaimana konteks dan proses dari kebijakan itu sendiri (Noer, 2019; Noer \& Madewanti, 2020). Kedua, berbagai penelitian mengabaikan subjek terpenting dari kebijakan: remaja perempuan. Berbagai penelitian lebih fokus pada bagaimana kebijakan dilaksanakan oleh BKKBN dan mengabaikan remaja perempuan sebagai objek sekaligus subjek kebijakan. Padahal ketika bicara mengenai program GenRe Ceria, terlebih dikaitkan dengan risiko Triad KKR, remaja perempuan adalah basis sebagai tujuan dari kebijakan, sehingga mengabaikan respon dari remaja perempuan sebagai penerima kebijakan adalah pengabaian atas kebutuhan dan pengalaman remaja perempuan.

Tulisan ini bertujuan untuk mengevaluasi program Generasi Berencana di DKI Jakarta dengan menggunakan CIPP Evaluation Model pada PIK R/M di enam sekolah di DKI Jakarta Barat yang menjadi ujung tombak dalam upaya memberikan akses layanan dan informasi kesehatan reproduksi bagi remaja perempuan. Evaluasi ini menjadi sangat krusial, sebab sejak digulirkan pada 2015, PIK R/M belum pernah dievaluasi secara serius, terutama dalam empat level: context, input, process, dan product. Penelitian program GenRe Ceria, diharapkan dapat memberikan gambaran bagaimana pelaksanaan, pemetaan kendala, sekaligus rekomendasi untuk perbaikan program yang akan datang.

\section{Metode Penelitian}

Penelitian ini mempergunakan metode penelitian kualitatif, dengan melakukan wawancara kepada delapan belas orang informan yang terdiri atas pemangku kebijakan, dalam hal ini BKKBN DKI Jakarta, PIK R/M di enam sekolah, siswa sekolah yang mengakses layanan PIK R/M dan remaja di sekitar sekolah tersebut. Selain itu, penelitian ini juga menggunakan observasi partisipasi dalam mengikuti seluruh kegiatan PIK R/M di enam sekolah di DKI Jakarta

\section{Hasil dan Pembahasan}

\section{A. Mengapa program ini penting?}

Genre adalah suatu program dari singkatan Generasi Yang Punya Rencana, yang diluncurkan oleh pemerintah melalui Badan Kependudukan dan Keluarga Berencana Nasional. Program ini merupakan salah satu program unggulan yang merupakan bagian dari Program Kependudukan Keluarga Berencana dan Pembangunan Keluarga 
(KKBPK) yang cetuskan oleh BKKBN. Program GenRe Ceria menyasar kepada usia remaja antara 10-24 tahun dan belum menikah. Program ini merupakan suatu program yang dikembangkan dan dilaksanakan untuk mempersiapkan kehidupan berkeluarga bagi remaja. Secara khusus, program ini bertujuan untuk membentuk remaja yang memahami hak-hak reproduksi, berperilaku hidup sehat, dan terhindar dari risiko kehamilan yang tidak diinginkan, pernikahan usia anak dan penyalahgunaan narkotika. Sasaran pelaksanaan program GenRe meliputi dua hal, diantaranya adalah melalui pendekatan kepada remaja langsung yang melalui kegiatan PIK dan pendekatan kepada keluarga yang mempunyai anak berusia remaja melalui wadah Bina Keluarga Remaja (BKR)

Program ini melibatkan anak sebaya sebagai duta dengan pembekalanpembekalan serta modul-modul yang sesuai dengan usianya diharapkan mampu mendekatkan program inipada sasarannya yaitu remaja Indonesia. Selain duta GenRe, ada juga konselor sebaya yang memiliki fungsi untuk menangani segala permasalahan remaja, dimana remaja yangmemiliki masalah dan ingin berkonsultasi dapat langsung menemui konselor yang terdapat pada setiap kelompok PIK-R/M, sehingga remaja dapat mendapatkan solusi dari segala permasalahannya tanpa harus mencari pelarian ke jalur yang salah. Konselor GenRe sendiri adalah remaja yang sudah diberikan/memiliki bekal ilmu sehingga bisa memberikan solusi terbaik dari setiap permasalahan yang dialami oleh remaja.

Salah satu dari pelaksanaan program GenRe ini adalah dengan terbentuknya Pusat Informasi dan Konseling Remaja/Mahasiswa (PIK R/M) yang sistem pengelolaannya dari, oleh, dan untuk remaja. Secara umum kegiatan dalam PIK R/M diantaranya adalah pemberian informasi dan konseling tentang Pendewasaan Usia Perkawinan (PUP), Kesehatan Reproduksi Remaja (KRR) yang meliputi informasi seksualitas dan kesehatan reproduksi, HIV/AIDS, narkotika dan psikotropika, serta keterampilan hidup yang meliputi keterampilan advokasi dan KIE (Komunikasi, Informasi dan Edukasi).

Selain kelompok PIK-R, ada pula kelompok BKR (Bina Keluarga Remaja) sebagai strategi pendekatan terhadap orang tua dari program GenRe yang dilakukan oleh sekelompok keluarga/ orangtua untuk meningkatkan bimbingan dan pembinaan tumbuh kembang remaja secara baik dan terarah dalam rangka membangun keluarga yang berkualitas juga harus terus mendapat perhatian dari semua pihak terutama orang tua dan tokoh masyarakat. Pengembangan kelompok Bina Keluarga Remaja (BKR) dapat membantu orangtua dalam memahami remaja, permasalahan remaja dan cara berkomunikasi dengan remaja. Melalui kelompok BKR setiap keluarga yang memiliki remaja dapat saling bertukar informasi dan berdiskusi bersama tentang hal-hal yang berkaitan dengan remaja. Permasalahan di DKI Jakarta yang berkaitan erat atau menjadi latar belakang terciptanya Program Kependudukan, Keluarga Berenacana dan Pembangunan Keluarga (PKKBPK) oleh BKKBN yang menjadi landasan terciptanya Program GenRe antara lain adalah masalah masalah kepadatan penduduk, penggunaan 
narkotika dan psikotropika dan perkawinan anak. Secara kuantitas, jumlah penduduk DKI Jakarta mengalami peningkatan.

Pada tahun 2010 angka populasi penduduk di DKI Jakarta sebanyak 9.607.787 jiwa dan meningkat menjadi 10.645.498 jiwa pada tahun 2020 (BPS 2020). Artinya dalam kurun waktu satu dekade, penduduk Jakarta bertambah lebih dari satu juta jiwa. Sejalan dengan meningkatnya jumlah penduduk adalah penduduk usia remaja yang juga meningkat setiap tahunnya. Setiap tahunnya, peningkatan jumlah remaja di DKI Jakarta mencapai 6\% setiap tahunnya, dari 1.453 .056 orang di tahun 2017 menjadi 1.541 .400 orang di tahun 2020. Jumlah penduduk usia remaja yang meningkat setiap tahun mendorong program GenRe Ceria yang dilakukan oleh BKKBN DKI Jakarta menjadi sangat krusial untuk dilakukan. BKKBN menyebutkan bahwa masalah yang menonjol dikalangan remaja yaitu permasalahan seputar tiga hal yang berkaitan dengan kesehatan reproduksi remaja, yakni tingginya angka prevalensi HIV/AIDS, penyalahgunaan narkotika, psikotropika dan zat adiktif dan median usia kawin pertama perempuan relatif masih rendah (MoWECP, 2019, 2020).

Khusus untuk median usia kawin pertama bagi perempuan, data BKKBN sesungguhnya menggambarkan bahkan Jakarta yang dianggap sebagai pusat urbanisme dan pendidikan, perkawinan anak masih sangat banyak dilakukan. Data Survei Demografi dan Kesehatan Indonesia (SDKI) untuk wilayah DKI Jakarta menyebut, bahwa pada tahun 2017, jumlah perempuan yang menikah sebelum berusia 16 tahun sebesar 8,12\% dan usia antara 17-20 tahun mencapai 32,63\%; sedangkan kehamilan pertama perempuan di bawah usia 16 tahun sebesar 2,73\% dan usia antara 17-20 tahun sebesar 26,12\%. Secara sederhana, 1 dari perempuan di DKI Jakarta menikah sebelum usia 20 tahun dan 1 dari empat perempuan telah memiliki anak pertama sebelum berusia 20 tahun (MoWECP \& CBS, 2017).

Berdasarkan kondisi yang ada, tidak mengherankan jika BKKBN gencar mensosialisasikan melalui Program GenRe kepada para remaja bahwasannya usia menikah ideal bagi perempuan 21 tahun dan pria 25 tahun, meski hal ini tidak sesuai dengan UU 1/74 yang menyatakan batas minimal usia menikah bagi perempuan 16 tahun dan pria 19 tahun. Meski berdasarkan putusan Mahkamah Konstitusi terkait peningkatan usia menikah telah direvisi menjadi usia menikah perempuan berumur 19 tahun. Berdasarkan ilmu kesehatan, umur ideal yang matang secara biologis dan psikologis adalah 20-25 tahun bagi wanita dan umur 25-30 tahun bagi pria. Usia tersebut dianggap masa yang paling baik untuk berumah tangga, karena sudah matang, emosisudah stabil dan bisa berpikir dewasa secara rata-rata. Rekomendasi ini ditujukan demi untuk kebaikan masyarakat, agar pasangan yangbaru menikah memiliki kesiapan matang seperti kedewasaan berpikir dan bertindak pada setiap guncangan yang muncul, baik guncangan akibat ekonomi, masalah internal maupun eksternal dalam mengarungi rumah tangga, sehingga dalam keluarga juga tercipta hubungan yang harmonis dan berkualitas.

Permasalahan lain yang dihadapi remaja adalah godaan penggunaan dan peredaran narkotika, psikotropika dan zat adiktif). Menurut World Drugs Reports 2018 
yang diterbitkan United Nations Office on Drugs and Crime (UNODC), menyebutkan sebanyak 275 juta penduduk di dunia atau 5,6 \% dari penduduk dunia(usia 15-64 tahun) pernah mengonsumsi narkoba. Sementara di Indonesia, BNN selaku focal point di bidang Pencegahan dan Pemberantasan Penyalahgunaan dan Peredaran Gelap Narkoba (P4GN) mengantongi angka penyalahgunaan narkoba tahun 2017 sebanyak 3.376.115 orang pada rentang usia 10-59 tahun. Bahkan laporan UNODC menyebut pada tahun 2015, jumlah perempuan pengguna narkotika adalah setengah dari pengguna laki-laki.

Sedangkan angka penyalahgunaan narkotika di kalangan pelajar di tahun 2018 (dari 13 ibukota provinsi di Indonesia) mencapai angka 2,29 juta orang. Salah satu kelompok masyarakat yang rawan terpapar penyalahgunaan narkoba adalah mereka yang berada pada rentang usia 15-35 tahun atau generasi milenial. Usia rentan atau labil pada remaja inilah yang sering dijadikan pemicu awal dalam keinginan untuk mencobacoba banyak hal termasuk narkoba (Purwatiningsih, 2001; Suyatna, 2018).

Data angka penyalahgunaan dan peredaran narkotika di kota-kota di Indonesia yang tertinggi pada tahun 2018 menurut tingkat pendidikan. DKI Jakarta mendapatkan urutan ke empat tertinggi setelah Surabaya, Samarinda dan Bandung. Hal ini masih menjadi pekerjaan yang berat untuk Pemerintah Daerah Provinsi DKI Jakarta, oleh karena itu Perwakilan BKKBN di Provinsi DKI Jakarta atau Dinas Pemberdayaan Perlindungan Anak dan Pengendalian Penduduk Provinsi DKI Jakarta masih harus bekerja keras dalam mensosialisasikan program GenRe agar para remaja memahami dampak buruk dari penggunaan narkotika.

\section{B. Analisis evaluasi CIPP}

Kerangka evaluasi CIPP dikembangkan sebagai sarana untuk menghubungkan evaluasi dengan pengambilan keputusan program. Hal ini bertujuan untuk memberikan dasar analitik dan rasional untuk pengambilan keputusan program, berdasarkan siklus perencanaan, penataan, pelaksanaan dan peninjauan dan revisi keputusan, masingmasing diperiksa melalui aspek evaluasi yang berbeda, baik evaluasi konteks, masukan, proses dan produk.

Model ini merupakan upaya untuk membuat evaluasi relevan secara langsung dengan kebutuhan pengambil keputusan selama fase dan kegiatan suatu program. Model evaluasi konteks, masukan, proses dan produk direkomendasikan sebagai kerangka kerja untuk memandu secara sistematis konsepsi, desain, implementasi dan penilaian proyek pembelajaran layanan, sekaligus memberikan umpan balik dan penilaian efektivitas untuk perbaikan berkelanjutan.

Model CIPP ini sangat unik, pada setiap tipe evaluasi terkait pada perangkat pengambil keputusan yang menyangkut perencanaan dan operasional sebuah program. Keunggulan model CIPP memberikan suatu format evaluasi yang komprehensif dan menyeluruh pada setiap tahapan evaluasi yaitu tahap konteks, masukan, proses dan produk. Model CIPP ini bertitik tolak pada pandangan bahwa keberhasilan program pendidikan dipengaruhi oleh berbagai faktor, seperti karakteristik peserta didik dan lingkungan, tujuan program dan peralatan yang digunakan, prosedur dan mekanisme 
pelaksanaan program itu sendiri. Dalam hal ini Stufflebeam melihat tujuan evaluasi sebagai: (a) Penetapan dan penyediaan informasi yang bermanfaat untuk menilai keputusan alternatif, (b) Membantu audience untuk menilai dan mengembangkan manfaat programpendidikan atau obyek, dan (c) Membantu pengembangan kebijakan dan program.

Dalam konteks program GenRe Ceria, model CIPP digunakan untuk mengevaluasi program dari dua indikator utama, yakni pemahaman remaja perempuan terkait kesehatan reproduksi dan mitigasi risiko penyalahgunaan narkotika dan zat adiktif lainnya.

Context Evaluation (evaluasi konteks) yang utama adalah untuk mengetahui kelebihan dan kelemahan yang dimiliki evaluan, sehingga apabila terdapat kelebihan maka harus dipertahankan sedangkan apabila terlihat kelemahan maka dapat diberikan alasan untuk dilakukan perbaikan yang dibutuhkan terutama terkait dengan tujuan, prioritas dan sasaran awal pada saat dibuatnya suatu program.

Berdasarkan konteks dapat diketahui bahwa tujuan, prioritas dan sasaran masyarakat yang ada dalam program ini sudah cukup baik secara keseluruhan, di mana program ini mencoba menyelaraskan kebutuhan jasmani dan rohani bagi para remaja. Adanya ide melakukan kursus atau pelatihan pra nikah yang bersertifikat jadi mereka benar-benar sudah memahami hak dan kewajiban suami istri sesuai dengan aturan yang ada dan kesiapan mental dan spiritual mereka.

Kekurangannya adalah di koordinasi dan kerjasama antara para pembina PIK $\mathrm{R} / \mathrm{M}$ dan forum GenRe yang masih perlu ditingkatkan lagi, selain itu jangkauan programnya juga masih kurang luas karena mereka hanya menyasar yang berbasis pendidikan melalui sekolah. Pada sisi lain, PIK R/M yang berbasis masyarakat masih minim, sedangkan masyarakat atau remaja di lokasi penelitian diketahui memiliki tingkat pendidikan yang rendah bahkan banyak dari mereka yang putus sekolah, sehingga mereka sama sekali tidak merasa pernah melihat, belum tahu, bahkan belum pernah mendengar adanya program ini diselenggarakan di tempat mereka. Di sisi lain, program ini dapat pula masuk dalam bagian dari progam Sekolah Ramah Anak (SRA), sebab ada beberapa bagian dari program yang sejalan dan beririsan dengan kebijakan SRA, salah satunya adalah hak anak atas perlindungan dari kekerasan dan akses layanan kesehatan (Na'imah, Widyasari, \& Herdian, 2020; Tresiana, Duadji, Fahmi, \& Putri, 2018; Ratnasari Diah Utami, Kurniasih, \& Kartikasari, 2017; Wuryandani, Faturrohman, Senen, \& Haryani, 2018)

Input Evaluation (evaluasi masukan) yang utama adalah mengevaluasi apakah sumberdaya (anggaran, sumber daya manusia, sarana dan prasarana) yang disediakan sudah sesuai atau belum dalam mendukung suksesnya pelaksanaan suatu program demi tercapainya tujuan atau target awal dibuatnya suatu program.

Berdasarkan evaluasi Input (evaluasi masukan), maka dapat diketahui bahwa anggaran yang diberikan untuk pelaksanaan program ini juga sudah cukup baik, namun dirasa masih sangat kurang apabila kita benar-benar berniat untuk mencetak generasi yang berkualitas baik, maka anggaran yang dikeluarkan juga harus besar, karena untuk 
mencetak Sumber Daya Manusia dibutuhkan biaya yang tidak sedikit. Sepertinya perlu anggaran guna bekerjasama dengan kementrian agama, untuk calon pengantin diadakan pelatihan khusus, minimal selama satu pekan dan akhirnya mendapatkan sertifikat siap nikah. Hal ini sangat perlu, terlepas dari yang memberikan sertifikat itu dari BKKBN ataupun Kementerian Agama, namun materi yang diberikan kepada para peserta sosialisasi program GenRe ini cukup baik dan dapat merubah cara pandang mereka terhadap masa depan menjadi lebih terencana,

Sedangkan untuk struktur pelaksanaan program yaitu wadah PIK-R juga sangat terstruktur dan cukup mumpuni dalam sumber daya manusia, sarana prasarana dalam pelaksanaan program sudah cukup baik, kendalanya adalah petugas lapangan sebagai Pembina PIK-R ini jumlahnya semakin sedikit dan usianya sudah cukup lanjut sehingga sudah tidak terlalu layak untuk mengurusi anak remaja ini.

Bagi banyak remaja khususnya di wilayah penelitian, masih agak sulit dan berat untuk dilakukan program ini karena kendala kultur masyarakatnya cenderung berlawanan dengan TRIAD KRR (No NAPZA, No Free Sex, No Pernikahan dini) yang dibawa sebagai semboyan di program GenRe ini, sehingga jika dilakukan pelaksanaan program GenRe, maka salah satu catatan yang harus diambil adalah bahwa program tersebut harus melibatkan tentara atau polisi dan ikut berpartisipasi dalam pelaksaan program serta pejabat setempat, membuat acara hiburan dan membawa uang saku atau bingkisan sembako sebagai alat penarik masa.

Evaluasi proses dengan model CIPP utamanya adalah untuk mengetahui seberapa berhasilnya kegiatan program GenRe ini dilaksanakan, apakah program terlaksana seperti rencana awal atau tidak. Selain itu evaluasi proses juga digunakan untuk mendeteksi atau memprediksi rancangan prosedur atau rancangan implementasi selama tahap implementasi terkait kelebihan, kelemahan, hambatan dan dukungan staf, menyediakan informasi untuk keputusan program dan sebagai arsip prosedur yang telah dilaksanakan.

Berdasarkan evaluasi proses, maka dapat diketahui bahwa memiliki kelebihan yaitu program GenRe ini rata-rata dapat mengubah cara berfikir para pesertanya terhadap Triad KKR dan lebih mau merencanakan masa depannya dengan lebih baik dan berkualitas lagi. Selain itu dengan adanya acara sosialisasi ini juga lebih mudah untuk diserap dan dipahami ilmunya dibandingkan hanya membaca di sebuah laman daring, sehingga bagi orang tua yang memiliki anak remaja merasa diajak diskusi oleh BKKBN cara mendidik anak dengan melalui program sosialisai GenRe ini.

Kekurangannya adalah anggarannya ditingkatkan lagi agar kegiatan program yang digarap bisa lebih banyak lagi, sumber daya manusianya sebagai pembina dan pengawas lapangannya kurang sekali, bahkan 1 orang bisa memegang 2-3 kelurahan dimana idealnya 1 kepala per kelurahan. Selain itu, koordinasi dan kerjasama antara Guru BK dan Ketua PIK atau Pengurus PIK-R Sekolah/Kampus juga harus ditingkatkan dan rajin ikut pelatihan agar bekal ilmu mereka dapat bisa dijadikan modal untuk meregenerasi pendidik sebaya dan konselor sebaya dengan kualitas dan keberlanjutan. 
Evaluasi produk dengan model CIPP utamanya adalah hasil yang diharapkan apakah sudah tercapai baik dari segi dampak, efektivitas, penyampaian dan keberlanjutan. yang pada akhirnya dapat membantu pimpinan atau pemegang keputusan terkait program yang sedang terlaksana, apakah program tersebut dilanjutkan, berakhir atau dilanjutkan dengan beberapa catatan.

Berdasarkan evaluasi produk, maka dapat diketahui dari segi metode, efektivitas dan dampak yang ditimbulkan dengan adanya program GenRe ini sudah bagus apabila dilihat dari nilai angka SFR yang dihasilkan sekarang ini menurut hasil survei SDKI angkanya 20 berarti artinya kita sudah mencapai target bahkan di atas target RPJMD diangka 21 dan setara dengan angka target RPJMN 2017 diangka 20, selain itu rata-rata peserta yang mengikuti program ini bisa langsung terpengaruhi untuk menubah cara pandang mereka terhadap masa depan dan cara pandang ini bisa bertahan lama bahkan bisa diturunkan ke generasi berikutnya.

Hal yang harus di perbaiki adalah ruang lingkup dan sasaran program GenRe ini harus lebih diperluas lagi, Program ini dilakukan secara lebih masif lagi, keseimbangan anggaran harus lebih diperhatikan demi keberlanjutan program, koordinasi antara dinasdinas terkait, lintas sektoral dan sumber daya manusia masih harus ditingkatkan, jumlah PKB atau pelaksana lapangannya yang terbatas harus bisa dicarikan solusi terhadap permasalahan tersebut, Kegiatan program ini harus mengikuti perkembangan zaman supaya lebih mudah diterima oleh remaja.

Hal lain yang perlu diperhatikan adalah respon masyarakat. Pada masyarakat di wilayah penelitian, hasil yang bisa diperoleh adalah sebagian remaja menginginkan perubahan setelah mengikuti program ini. Hal ini ditandai dengan pemahaman mereka atas bahaya seks bebas, risiko kehamilan yang tidak diinginkan, penyalahgunaan narkotika dan lain sebagainya. Di sisi lain, respon ini sangat bergantung pada konteks kultural masyarakat. Tantangan utamanya adalah mengubah cara berpikir masyarakatnya dan pola hidup mereka agar lebih maju, tentram dan damai, meski akan terasa sangat berat untuk pelaksanaan program GenRe untuk dapat sukses atau berhasil merubah kultur masyarakat. Solusi agar bisa mengubah sudut pandang remaja adalah setelah diberikan penyuluhan/sosialisasi ini warga tersebut diberikan jalur atau difasilitasi untuk keluar dari wilayah tersebut atau secara berkala dipantau ketika mereka menjalankan anjuran dari program Genre tersebut, karena apabila masih tinggal disitu maka akan tertarik kembali ke kehidupan kelam mereka sebelumnya.

\section{Kesimpulan}

Berdasarkam hasil dan pembahasan penelitian terkait evaluasi program Generasi Berencana (GenRe) yang dianalisis menggunakan metode CIPP yang terdiri dari empat indikator, yaitu Context, Input, Process, Product maka dapat ditarik kesimpulan bahwa Program Generasi Berencana secara umum sudah berjalan dengan baik di DKI Jakarta, hanya perlu perbaikan di beberapa indikator, seperti penambahan anggaran, penambahan sumber daya manusia di lapangan, serta perbaikan dan peningkatan 
koordinasi serta kerjasama lintas sektor terkait program ini antara lain BKKBN, Dinas Kesehatan, Dinas Pendidikan dan Kantor Urusan Agama.

Namun, program ini masih belum berjalan optimal dikarenakan jangkauan sasarannya yang belum terlalu luas. Hal ini karena program GenRe yang selama ini berjalan lebih fokus ke jalur pendidikan dan masih sangat minim untuk jalur masyarakat. Sedangkan menurut hasil penelitian di atas diterangkan bahwa di banyak penduduk Kecamatan Tamansari yang tidak bersekolah dan putus sekolah dikarenakan faktor kemiskinan. Selain itu, yang menjadi penghambat untuk dilaksanakannya Program GenRe secara masif disana antara lain karakter masyarakat yang cenderung tidak mudah menerima nasihat, dan kondisi lingkungan sosial masyarakat sehari-hari bertentangan dengan tujuan program GenRe yaitu untuk melaksanakan Triad KKR berupa tidak melakukan pergaulan bebas, tidak menggunakan narkotika dan tidak melakukan pernikahan dini. 


\section{Bibliografi}

Citrawathi, Desak Made, Adnyana, Putu Budi, Putu, Ni, \& Ratna, Sri. (2019). Kelompok Siswa Peduli Aids Dan Narkoba. 1084-1092.

Daud, Mohd Kalam, \& Dasmidar, Dasmidar. (2017). Program Generasi Berencana BKKBN Provinsi Aceh dan korelasinya dengan Adat Beguru dalam Masyarakat (Studi Kasus di Kecamatan Kutapanjang Kabupaten Gayo Lues). SAMARAH: Jurnal Hukum Keluarga Dan Hukum Islam, 1(1), 148. https://doi.org/10.22373/sjhk.v1i1.1574

Fitriyanti, D., \& Iswari, R. (2020). Sosialisasi Pembinaan Karakter dalam Program Generasi Berencana (GenRe) Melalui Pusat Informasi Konseling Mahasiswa (PIKMA) Sahabat Kota Pekalongan. Journal of Education, Society and Culture, 9(2), 1014-1025. Retrieved from $\mathrm{h}$

Liana, Intan. (2018). Efektivitas Program Generasi Berencana Pusat Informasi Konseling (Pik) Remaja Bagi Siswa Sma Negeri Di Kota Banda Aceh. AVERROUS: Jurnal Kedokteran Dan Kesehatan Malikussaleh, 4(2), 15. https://doi.org/10.29103/averrous.v4i2.1034

MoWECP. (2019). Ministry of Women Empowerment and Child Protection: Gender Equality Outlook 2018. Jakarta.

MoWECP. (2020). Ministry of Women Empowerment and Child Protection: Gender Equality Outlook 2019. Jakarta.

MoWECP, \& CBS. (2017). Ministry of Women Empowerment and Child Protection on Thematic Gender Statistics: End Violence against Women and Children in Indonesia. Jakarta.

Na'imah, Tri, Widyasari, Yuki, \& Herdian, Herdian. (2020). Implementasi Sekolah Ramah Anak untuk Membangun Nilai-Nilai Karakter Anak Usia Dini. Jurnal Obsesi: Jurnal Pendidikan Anak Usia Dini, 4(2), 747. https://doi.org/10.31004/obsesi.v4i2.283

Noer, Khaerul Umam. (2019). Mencegah Tindak Kekerasan pada Anak di Lembaga Pendidikan. Sawwa: Jurnal Studi Gender, 14(1), 47. https://doi.org/10.21580/sa.v14i1.2998

Noer, Khaerul Umam, \& Madewanti, Ni Loh Gusti. (2020). Too many Stages, Too Little Time: Bureaucratization and Impasse in the Social Safety Net Program in Indonesia. Jurnal Studi Pemerintahan, 11(3), 370-400.

Oktavia, Devie, Achdiani, Yani, \& Rinekasari, Nenden Reni. (2016). Analisis Penguasaan Pengetahuan Hasil Penyuluhan Pendewasaan Usia Perkawinan Dalam Program Generasi Berencana Pada Remaja Di SMP Negeri 39 Bandung. FamilyEdu: Jurnal Pendidikan Kesejahteraan Keluarga, 2(2), 70-80. 
Dewi Kartika Sari, Khaerul Umam Noer, Endang Rudiatin

Purwatiningsih, Sri. (2001). Penyalahgunaan Narkoba. Populasi, 12(1), 37-54.

Putri, Rike Septiyana Dwi, \& Larasati, Maulina. (2015). Kampanye Program Badan Kependudukan Dan Keluarga Berencana Nasional (BKKBN)(Survey Deskriptif: Rendahnya Partisipasi Kampanye Program Generasi Berencana (GenRe) Terkait Pendewasaan Usia PerkawinanPadaPendekatan Pusat Informasi Konseling (PIK) Remaja SMAN . Communicology: Jurnal Ilmu Komunikasi, 2(1), 4255. https://doi.org/10.21009/communicology.021.04

Pyas, Dwi Wiliantining, \& Satlita, Lena. (2017). Efektivitas Pelaksanaan Program Generasi Berencana Dalam Meningkatkan Kesehatan Reproduksi Remaja Di Kota Yogyakarta. Natapraja, 5(1), 97-106. https://doi.org/10.21831/jnp.v5i1.18756

Ridwan, Harnina, Juhaepa, \& Sarmadan. (2019). Analisis Jaringan Kerja Komunikasi BKKBN Dalam Sosialiasi Program Generasi Berencana (Genre) di Sulawesi Tenggara. Jurnal Komunikasi, Mas yarakatdanKea manan(K OMA $S$ K AM ), 1(1), 62-74.

Sari, Vitri Intan, \& Indrawadi, Junaidi. (2019). Pembentukan Karakter Remaja Kota Padang Melalui Program Generasi Berencana untuk Menghadapi Bonus Demografi 2030. Journal of Civic Education, 2(4), 283-294. https://doi.org/10.24036/jce.v2i4.254

Susanti, Herdiana Ayu. (2015). Strategi Komunikasi Badan Kependudukan dan Keluarga Berencana Nasional (BKKBN). Jurnal ASPIKOM, 2(4), 243. https://doi.org/10.24329/aspikom.v2i4.75

Suyatna, Uyat. (2018). Evaluasi Kebijakan Narkotika di Indonesia. Sosiohumaniora, 20(2), 168-176. https://doi.org/10.24198/sosiohumaniora.v20i2.16054

Tresiana, Novita, Duadji, Noverman, Fahmi, Teuku, \& Putri, Rahmah Dianti. (2018). Pelatihan Mendesain Kebijakan dan Strategi Sekolah Ramah Anak pada Satuan Pendidikan. Sakai Sambayan Jurnal Pengabdian Kepada Masyarakat, 2(1), 41. https://doi.org/10.23960/jss.v2i1.48

Utami, Devi Dwi Yana. (2015). Penyuluhan Program BKKBN Mengenai Generasi Berencana ( GenRe) dan Sikap Remaja. Jurnal Simbolika, 1(2), 199-210.

Utami, Ratnasari Diah, Kurniasih, Mulat, \& Kartikasari, Farida Nur. (2017). Implementasi Penerapan sekolah Ramah Anak pada Penyellenggaraan Pendidikan Sekolah Dasar. The 5th Urecol Proceeding, 18(February), 170-176.

Wuryandani, Wuri, Faturrohman, Faturrohman, Senen, Anwar, \& Haryani, Haryani. (2018). Implementasi pemenuhan hak anak melalui sekolah ramah anak. Jurnal Civics: Media Kajian Kewarganegaraan, 15(1), 86-94. https://doi.org/10.21831/jc.v15i1.19789 
Evaluasi Model CIPP Program Generasi Berencana di DKI Jakarta

Yulianti, Devi. (2017). Program Generasi Berencana (GenRe) Dalam Rangka Pembangunan Manusia Menuju Pembangunan Nasional Berkualitas. Jurnal Analisis Sosial Politik, 1(2), 93-108. 